\title{
Quantitative X-ray Microanalysis Of Submicron Carbide Formation In Chromium (III) Oxide Rich Scale
}

\author{
W. Keith Collins*, M. Ziomek-Moroz, G. R. Holcomb, P. Danielson, and A. Hunt \\ *National Energy Technology Laboratory, 1450 Queen Ave SW, Albany, Oregon 97321
}

This paper discusses the chemical microanalysis techniques adapted to identify the precipitates that form on the surface of, or within, the oxide scale of a Fe-22Cr ferritic steel during exposure to a carbon-monoxide rich environment at 750C for 800 hours [1]. Examination of oxidized test coupons revealed the presence of a fiber like structure at the surface, shown in figure 1. Other studies have reported that these structures are carbon precipitates [2].

Metallographic cross sections of the coupons were prepared to examine the microstructure of the scale formed. The surface previously examined by SEM was marked so the sectioned coupons would be examined in the same region as that described above. Mounts were given a thin coating of palladium for conductivity. Imaging using backscatter electrons at an accelerating voltage of $10 \mathrm{kV}$ detected the presence of submicron precipitates in the oxide film. Quantitative microanalysis at $10 \mathrm{kV}$ did not give enough data to identify the precipitates, as the excitation volume was too large.

The precipitate size was measured, and a Monte Carlo simulation was used to determine that an accelerating voltage of $4 \mathrm{kV}$ would minimize excitation of the oxide scale around the precipitate, and thus provide improved quantitative analysis. Because EDX default settings produced questionable results, standard reference spectra were acquired to calibrate the instrumentation and improve spectrum deconvolution. Results now identified some of the precipitates as a chrome-rich carbon-rich 64Cr6Fe30C as shown in Figure 2.

This low-kV analysis technique was also applied to the study of solid oxide fuel cell metal interconnects, and the diffusion of elements during high temperature exposures. In this application, aluminum, silicon and titanium can migrate from the base metal to the oxide film, inhibiting electrical conductivity. To determine if this was the case here, WDX analyses were included to improve the quantification of trace elements. In quantifying the microchemical analyses, no issues were found with the $\mathrm{Al}$ and $\mathrm{Si} \mathrm{K} \alpha$ lines, but the Ti, $\mathrm{Cr}$ and $\mathrm{Fe} \mathrm{L} \alpha \mathrm{X}$-ray lines proved to be problematic. At times the default background locations interfered with the main peak. More beam current was needed to excite the L $\alpha$ X-ray lines of the transition elements examined.

A grid analysis technique was devised to examine elemental dispersion within the interface region. This technique integrated the EDX and WDX detectors. The WDX was used to quantify the trace elements $\mathrm{Al}, \mathrm{Si}$ and $\mathrm{Ti}$, and the EDX used for the other elements of interest. The requirement for long acquire times meant that analyses take about 48 hours.

\section{References}

[1] M.Ziomek-Moroz et.al., Studies of Scale Formation and Kinetics of Crofer 22 APU and Haynes 230 CO-Containing Environments for SOFC Applications, 2006 Fuel Cell Seminar

[2] C. H. Toh, et. al., Materials at High Temperatures.20 (2003) 129 


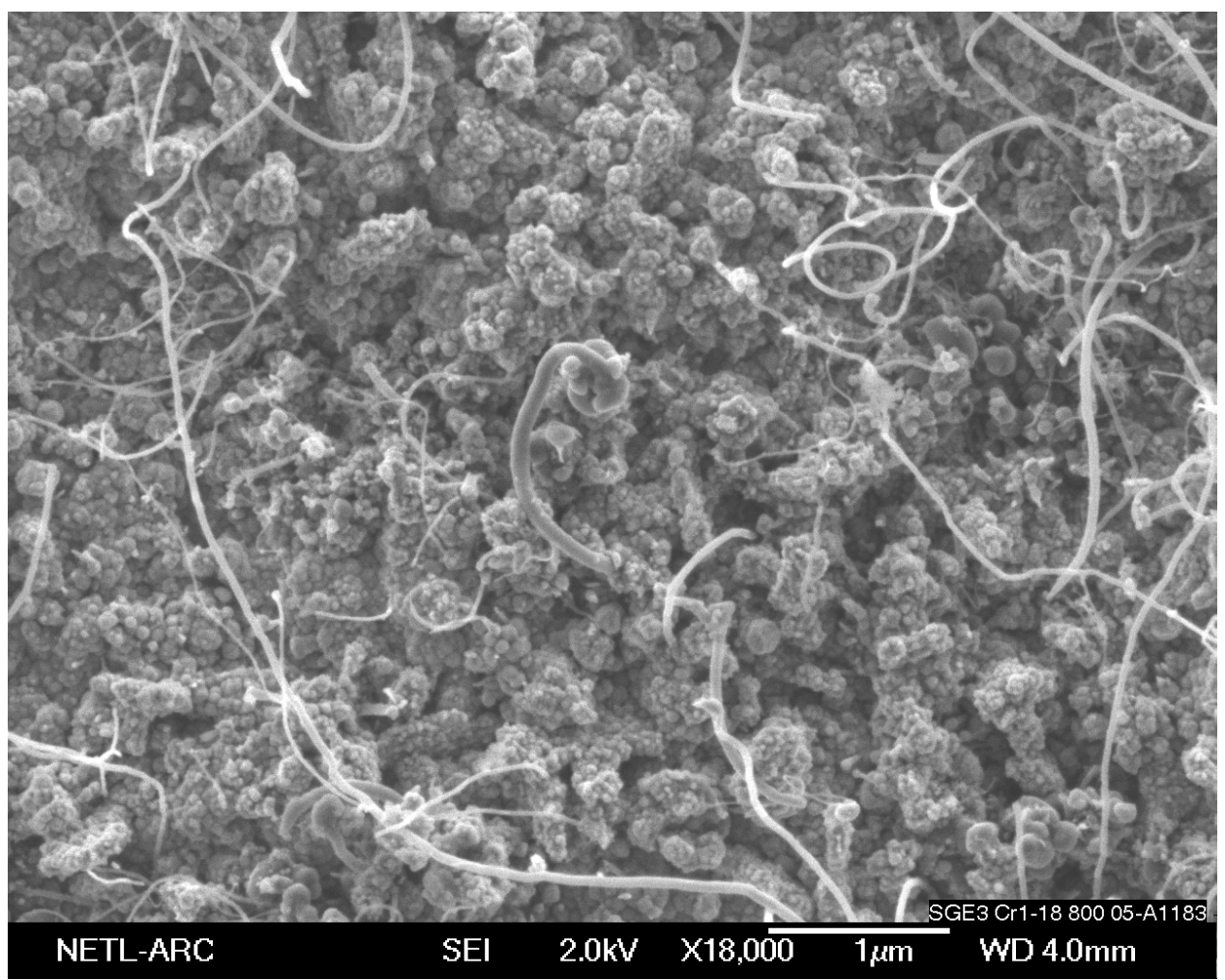

Fig. 1. Secondary electron micrograph of fiber like structures on a Fe-22Cr alloy after exposure to a $\mathrm{CO}$ rich atmosphere for 800 hours.

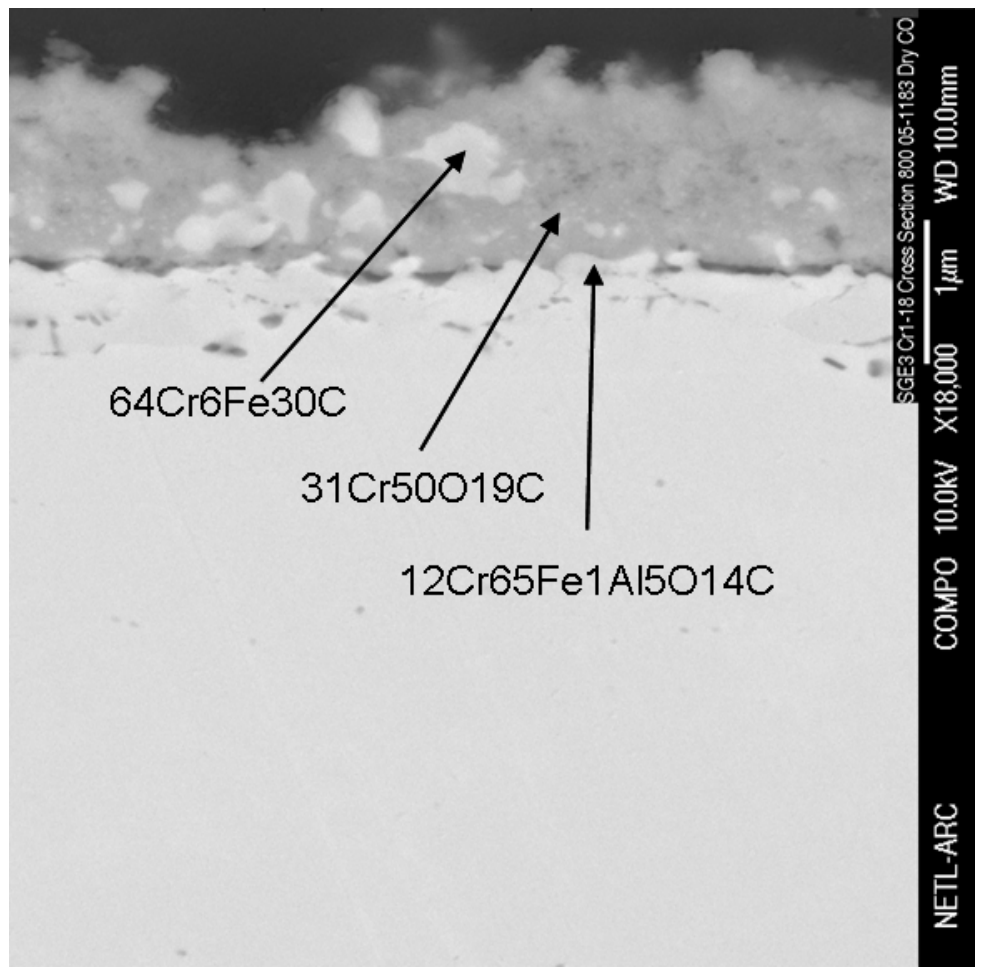

Fig. 2. Backscatter electron micrograph of metallographic cross section of a Fe-22Cr alloy with $\mathrm{M}_{7} \mathrm{C}_{3}$ carbide and other phases after exposure to a $\mathrm{CO}$ rich atmosphere for 800 hours. 


\title{
National Energy Technology Laboratory
}

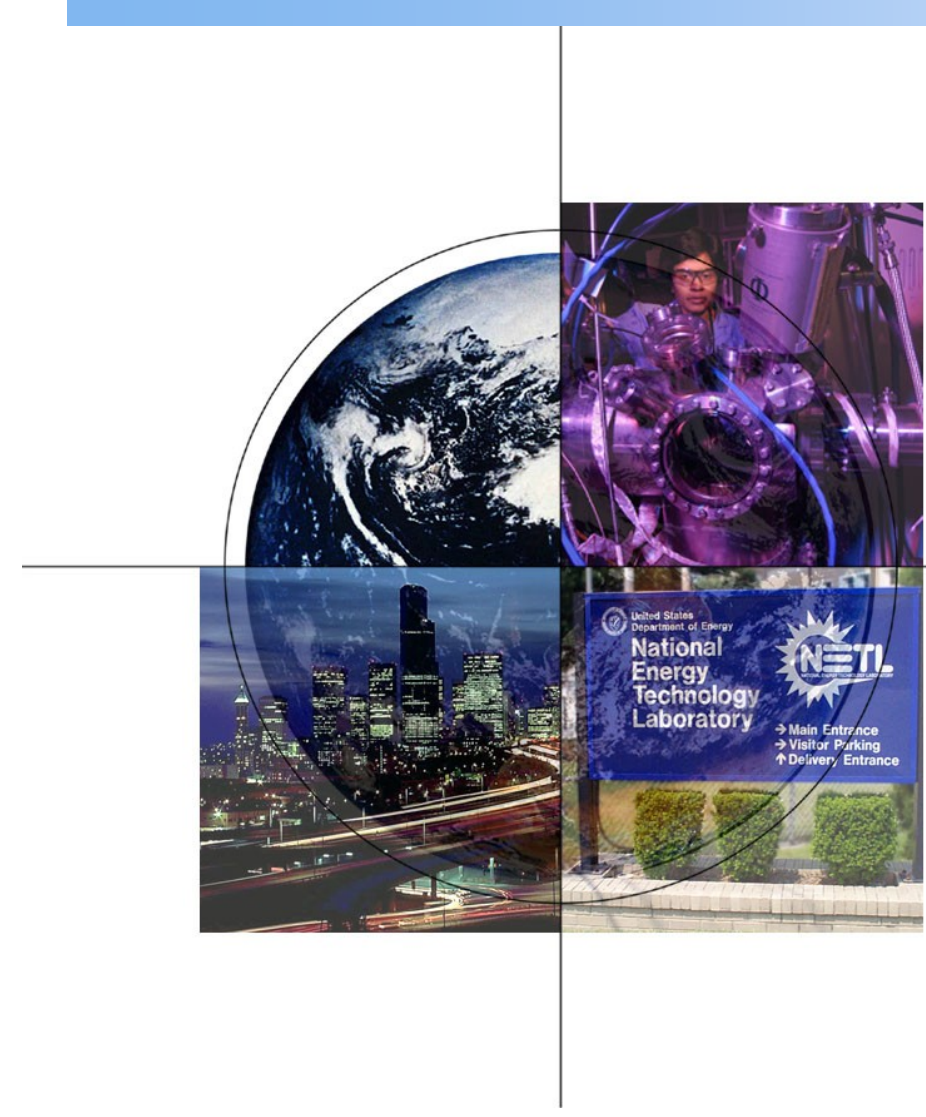

\author{
Quantitative X-ray \\ Microanalysis Of Submicron \\ Carbide Formation In \\ Chromium (III) Oxide Rich \\ Scale
}

W. Keith Collins*,

M. Ziomek-Moroz,

G. R. Holcomb,

P. Danielson, and

A. Hunt

National Energy Technology Laboratory

Office of Fossil Energy 
This paper will cover the microanalysis techniques used to identify carbide precipitates that formed on the surface and in the oxide film of a Fe $22 \mathrm{Cr}$ ferritic steel.

- Getting the metallographic cross sections to be in the general region of the surface examination.

- Sample preparation issues to be aware of.

- Problems with initial instrument setup

- Monte Carlo simulation to select a analysis kV

- EDX setup

- WDX

- the technique 


\section{Surface examination and cross sections in the same general area}

- Stage $X$ and $Y$ location was noted.

- Location of yellow dot let the operator know which side was the surface examined

- A small yellow dot of paint was placed on the coupon surface of the side examined

- Stage $X-Y$ data allowed the operator to position the cross section in the general are of surface examination 
$>$ How well is the sample mounted to the holder?

$>$ Magnetism. Is the sample only slightly magnetic?

> Metallographic preparation 


\section{Sample preparation issues}

Magnetism: Slightly magnetic samples will distort the beam enough to give poor images. It will cause high stress in the operator as the image does not stay focused.

Solution: Deqauss the sample

Examples: 304 Stainless Steel, High Chromium White Cast Irons 


\section{Sample preparation issues}

How well is the sample mounted to the holder?

A loose sample may vibrate or slide off the sample holder if tilted.

A magnetic sample may be drawn toward the final pole piece and hit the back scatter detector.

Worse yet small particles drawn into the column distorting imaging requiring service. 


\section{Sample preparation issues}

Metallographic preparation Sample Mounting

What mounting media was used?

Cold Mount: Epoxy

Hot Pressed: Bakelite

Etchants used (if any)

Does the mounting media have fillers such as $\mathrm{SiO}_{2}$ or $\mathrm{Al}_{2} \mathrm{O}_{3}$ will these have an effect on your analysis 


\section{Sample preparation issues}

Metallographic preparation Polishing

What polishing compounds were used.

SiC paper, diamonds and $\mathrm{SiO}_{2}$ or $\mathrm{Al}_{2} \mathrm{O}_{3}$

Polishing media can embed itself in the sample and look like a phase.

Edge rounding from polishing 


\section{Problems with initial instrument setup}

- What is need in the examination

- Type of Sample, Coupon or Cross Section

- Selecting the best kV, 10, 15 , or $20 \mathrm{kV}$ ?

- How is the sample mounted

- Conductive coating selected if used
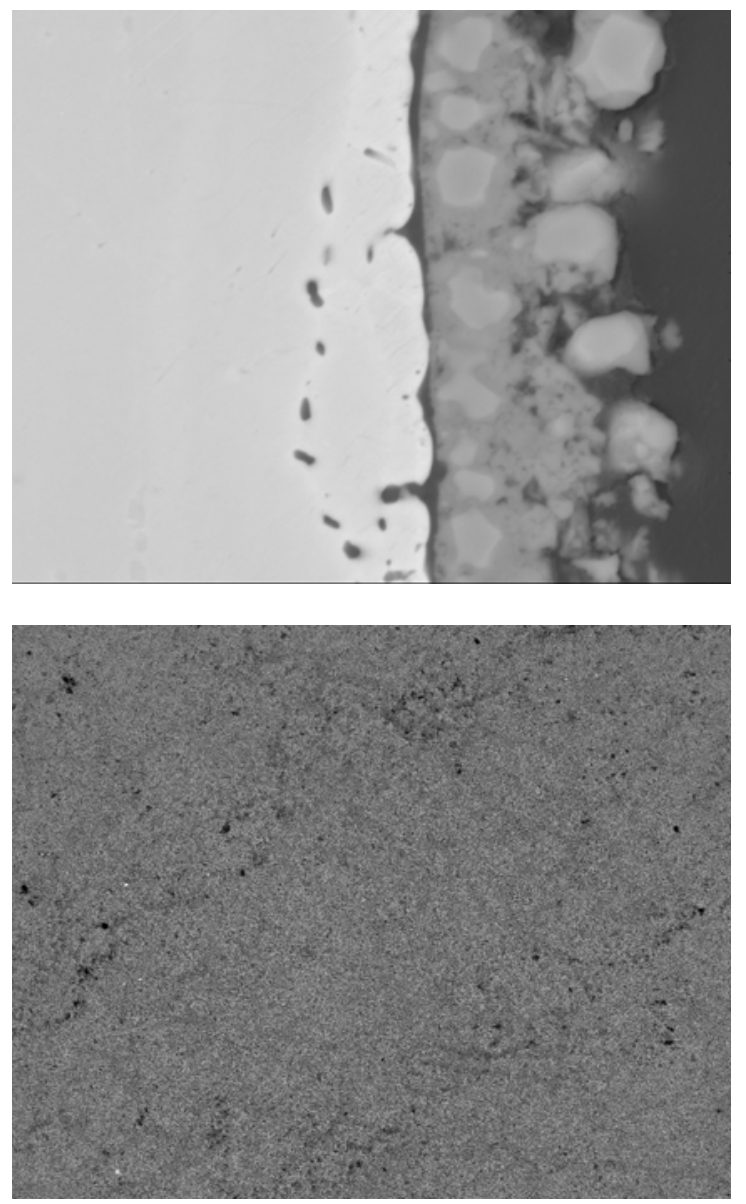


\section{Problems with initial instrument setup}

- Finding the unexpected

- What are those filaments?

- Adjusting the SEM for imaging

- The $\mathrm{kV}$ has been reduced to $2 \mathrm{kV}$ to reduce beam penetration

- Qualitative Analysis indicates $\mathrm{C}$ rich

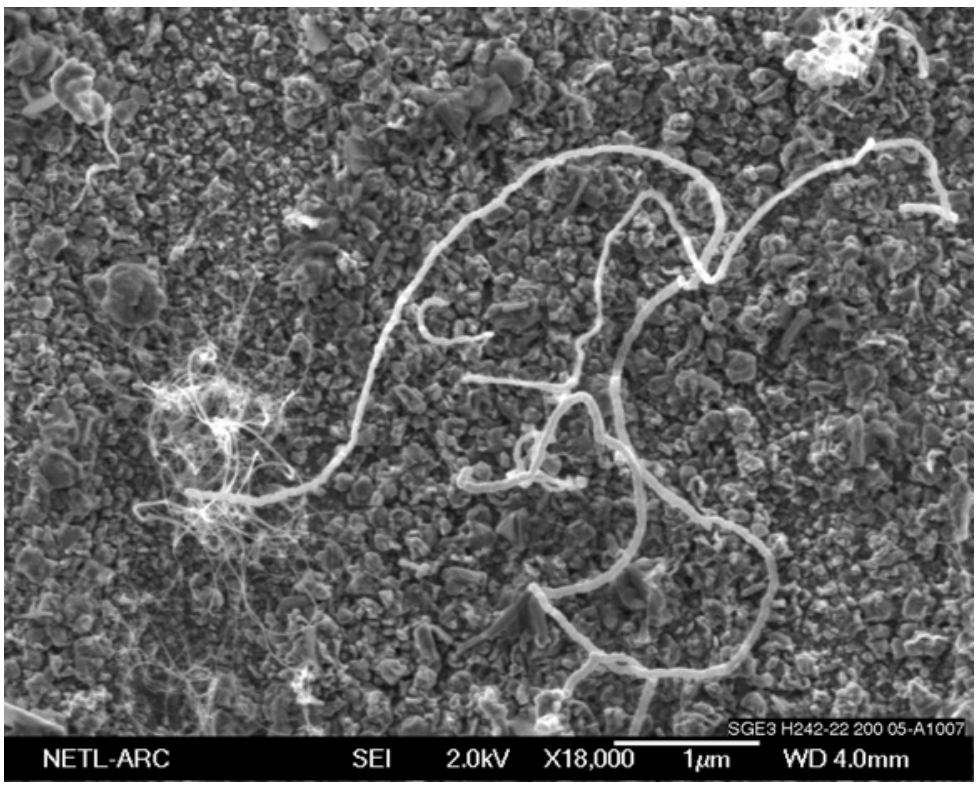




\section{Problems with initial instrument setup}

- Finding the unexpected

- What are those precipitates?

- Adjusting the SEM for analysis.

- Analysis vs. Imaging

- Determining a beam current to analysis the precipitates.

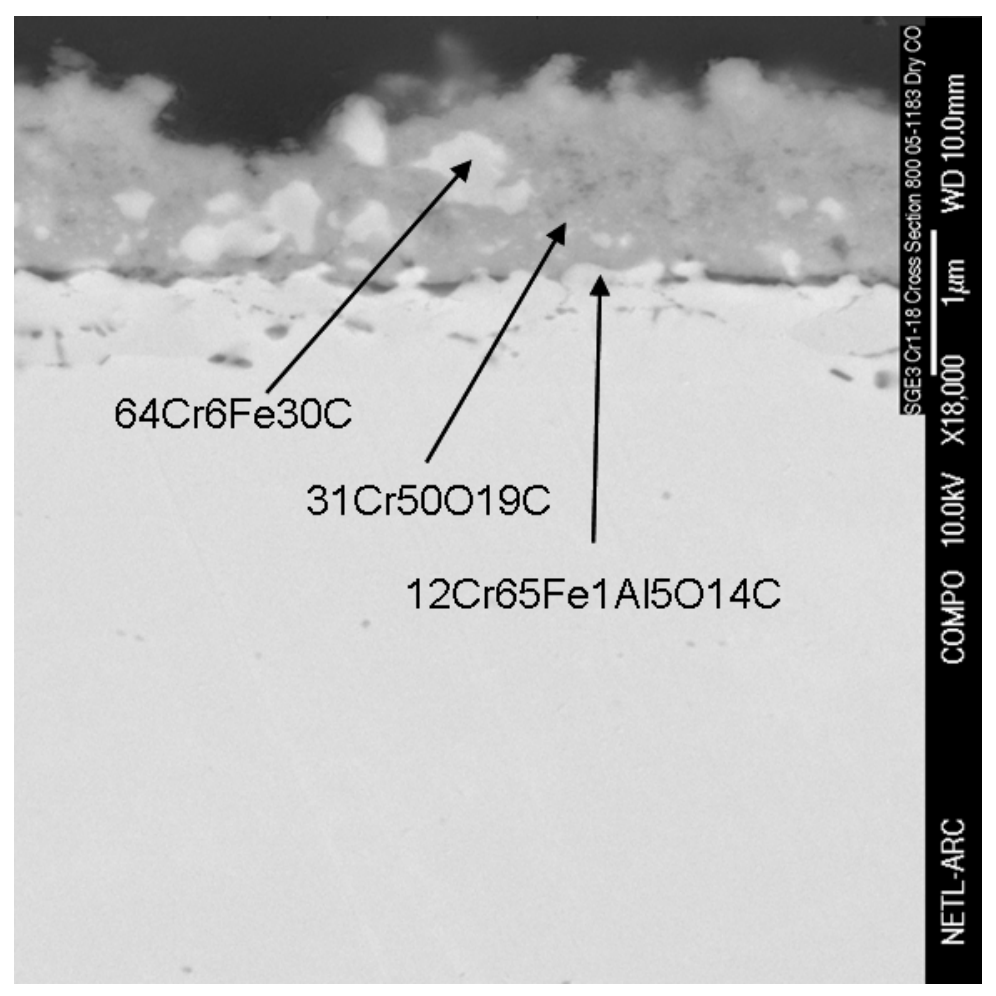




\section{Monte Carlo simulation to select a analysis kV}

- Determine particle diameter

- 0.1 to 0.5 micron

- Select a kV using Monte Carlo simulation software

- $10 \mathrm{kV}$

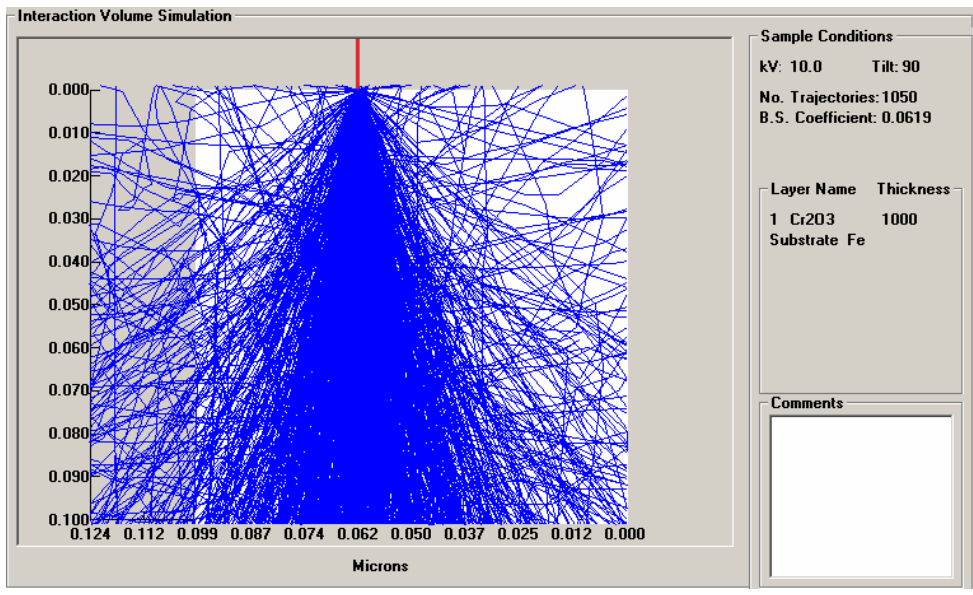




\section{Monte Carlo simulation to select a analysis kV}

- Determine particle diameter

- 0.1 to 0.5 micron

- Select a kV using Monte Carlo simulation software

- $10 \mathrm{kV}$ and $4 \mathrm{kV}$
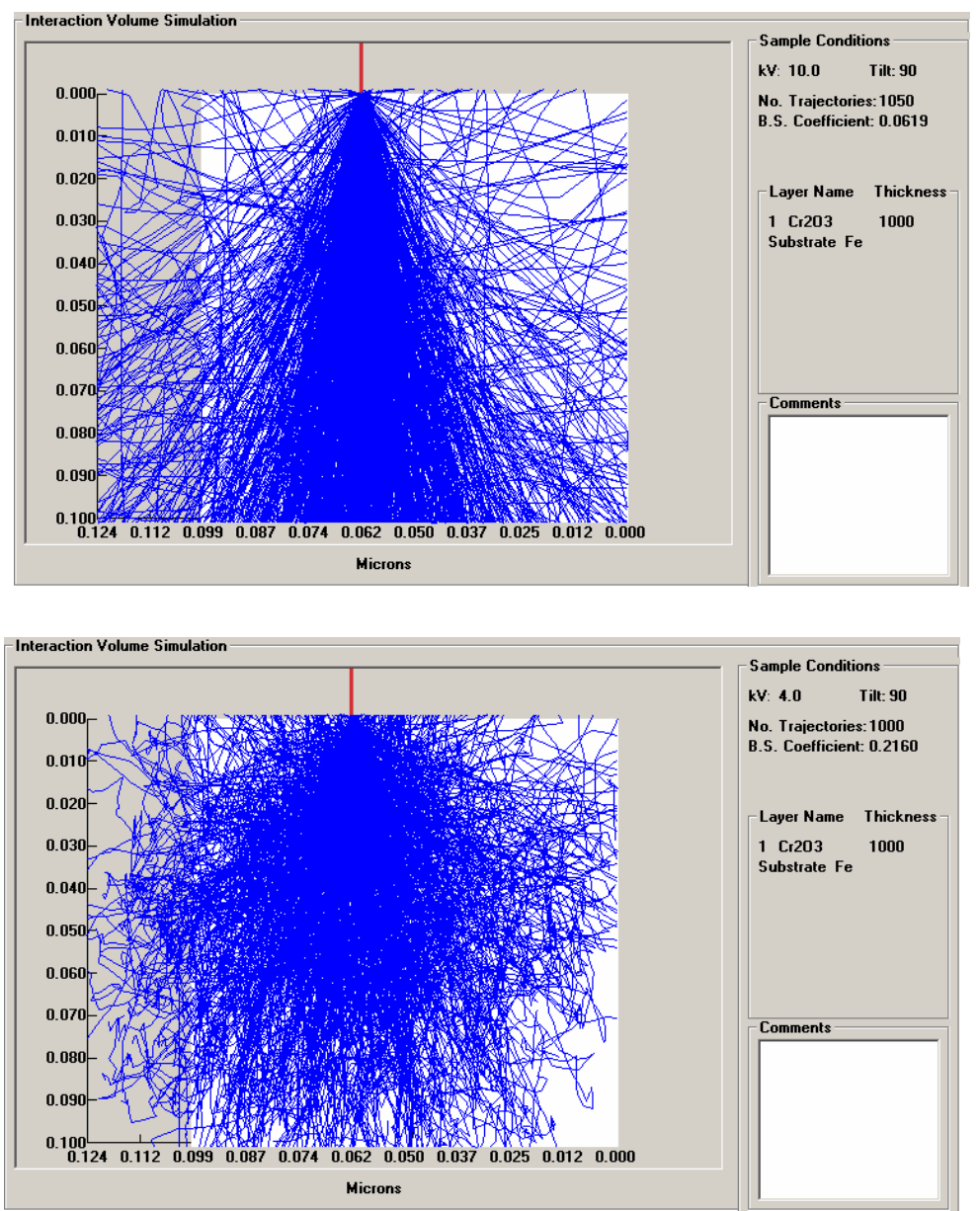


\section{Secondary Fluorescence}

- Dr. Fournelle of University of Wisconsin did a Penelope analysis at $15 \mathrm{kv}$ and found

- Fe Ka at 0.5 um from interface is $2.7 \%$

- Fe $\mathrm{Ka}$ at $1 \mathrm{um}$ from interface $1.4 \%$

- Conclusions very small amount of Fe Ka X-rays from the base metal

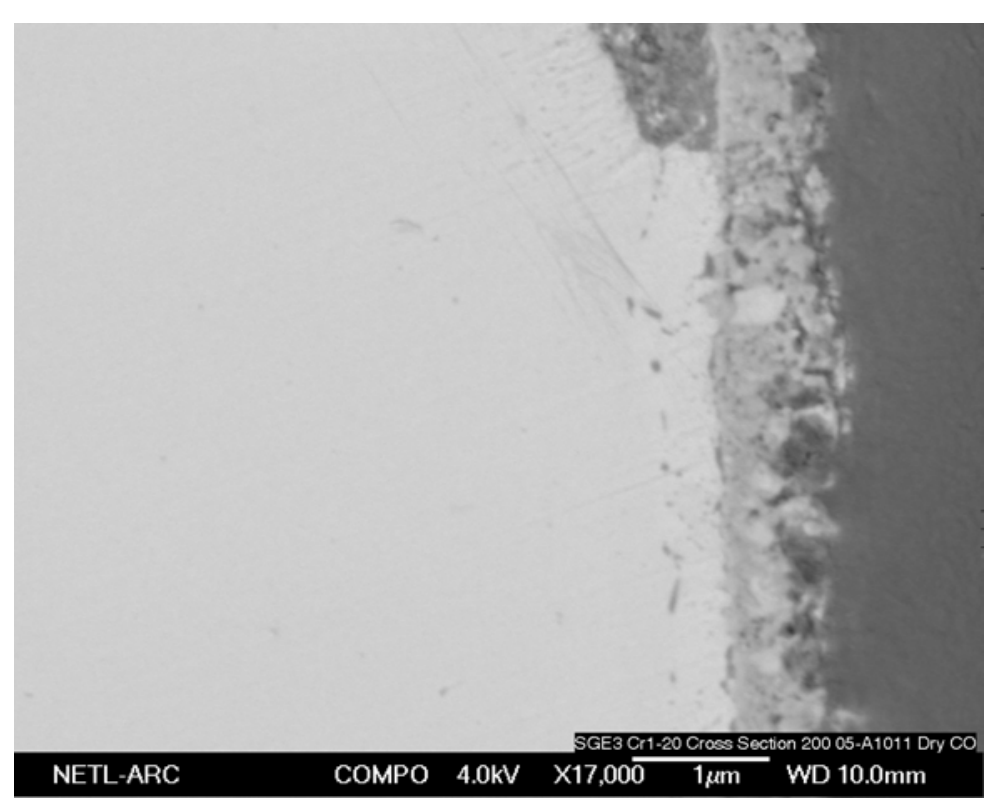
affecting in the Oxide . 


\section{Instrument Setup EDX}

- The EDX analysis instrument will most likely need to be setup for low $\mathrm{kV}$ analysis.

- Acquire standard reference spectra as needed

- Standardize the instrument

- Verify that it works 


\section{Interesting Auto ID}
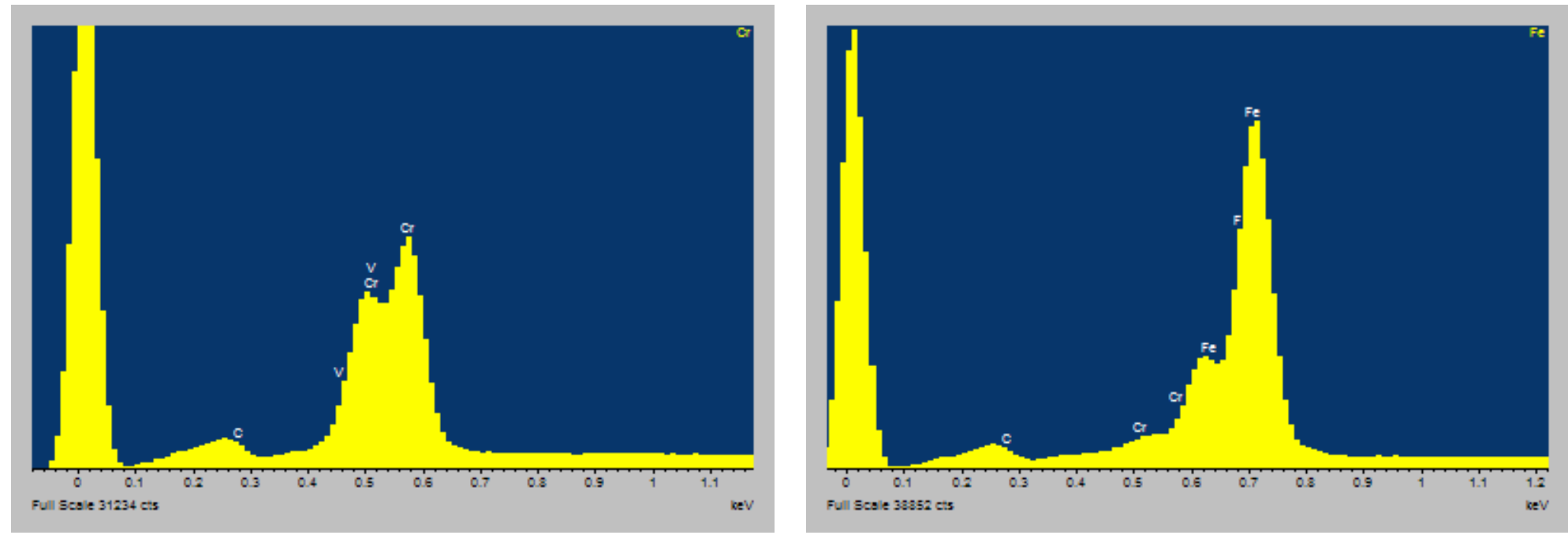

Cr L $\alpha$

Fe L $\alpha$ 


\section{Analytical Check Results}

\begin{tabular}{|c|c|c|c|c|c|}
\hline Element & Weight\% & Atomic\% & Element & Weight\% & Atomic\% \\
\hline Fe L(50\%) & 49.61 & 50.86 & Co L(50\%) & 49.98 & 49.89 \\
\hline Ni L(50\%) & 50.39 & 49.14 & Ni L(50\%) & 50.02 & 50.11 \\
\hline Totals & 100 & & Totals & 100 & \\
\hline Element & Weight\% & Atomic\% & $\begin{array}{l}\text { Element } \\
\text { Cr7C3 }\end{array}$ & Weight\% & Atomic\% \\
\hline Fe L(50\%) & 47.33 & 48.67 & C K(9\%) & 8.71 & 29.24 \\
\hline Co L(50\%) & 52.67 & 51.33 & Cr L(91\%) & 91.29 & 70.76 \\
\hline Totals & 100 & & Totals & 100 & \\
\hline
\end{tabular}




\section{WDX SETUP}

- WDX setup for the $L$ lines is similar to that of $K$ lines.

- Verify that the default settings are correct

- Check background settings for overlaps and position is usable. 


\section{Titanium L $\alpha$ Background Lines}

Default

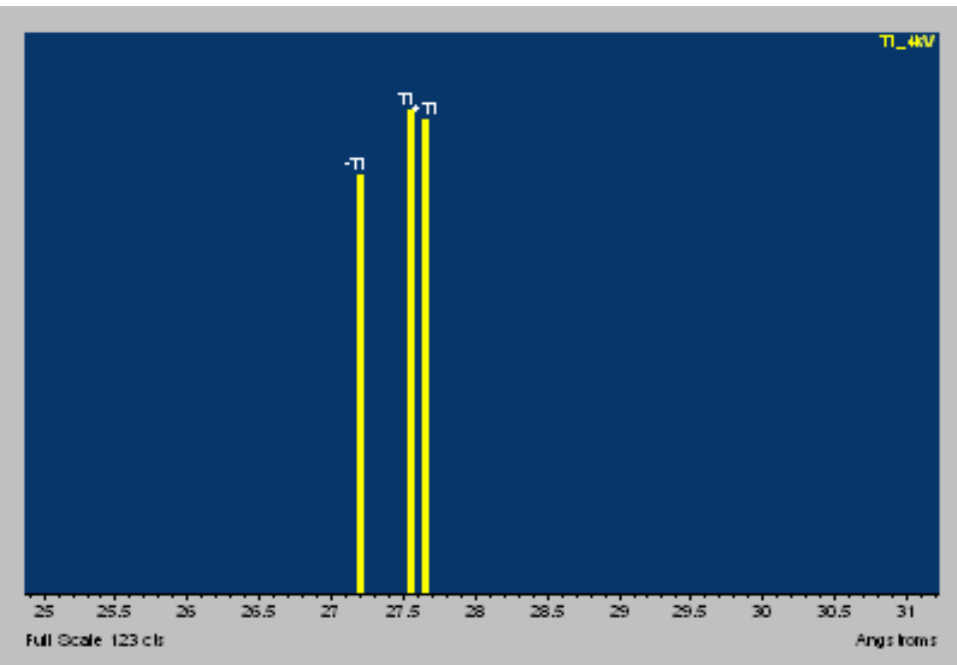

Adjusted

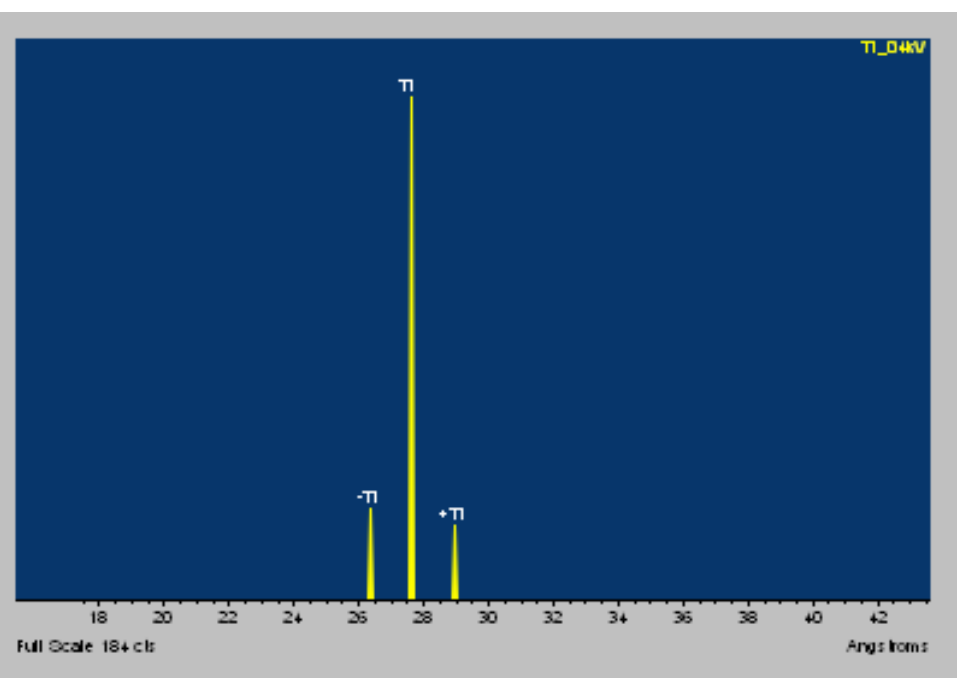




\section{The Analysis}

- Surface roughness effects results

- Results only qualitative

- Precipitates to small to analyze

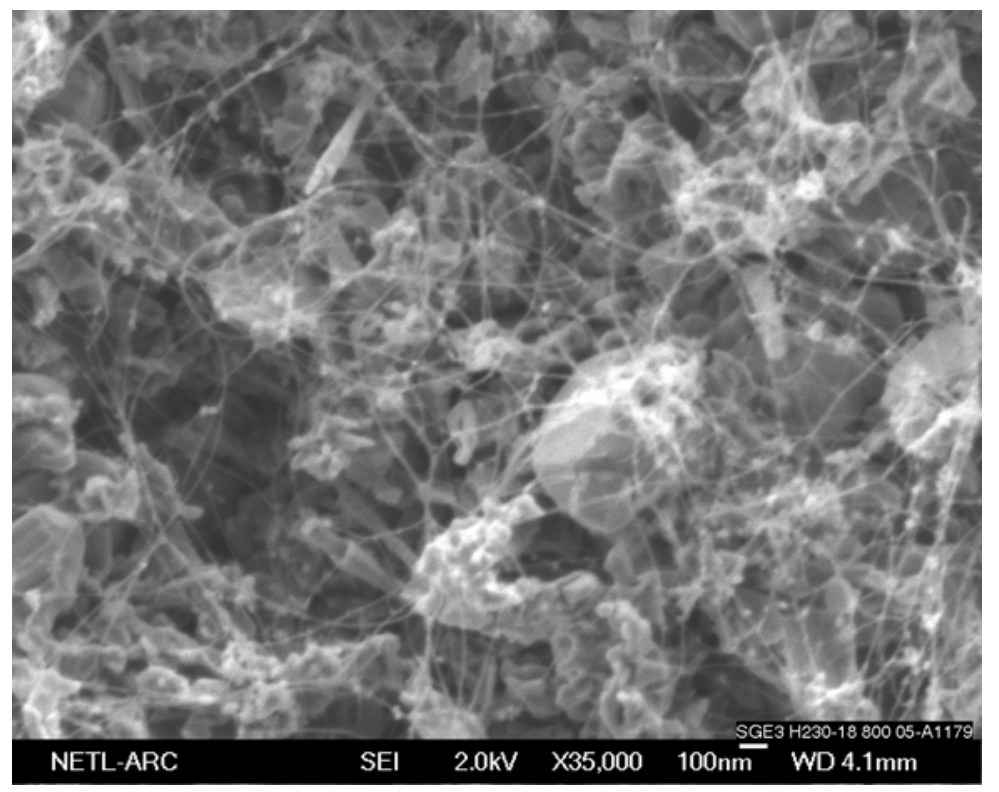




\section{The Analysis}

- Edge rounding effects results

- Secondary fluorescence from base metal, oxide and mounting media

- Small precipitates need low kV analysis techniques

- The precipitates are transition compounds.

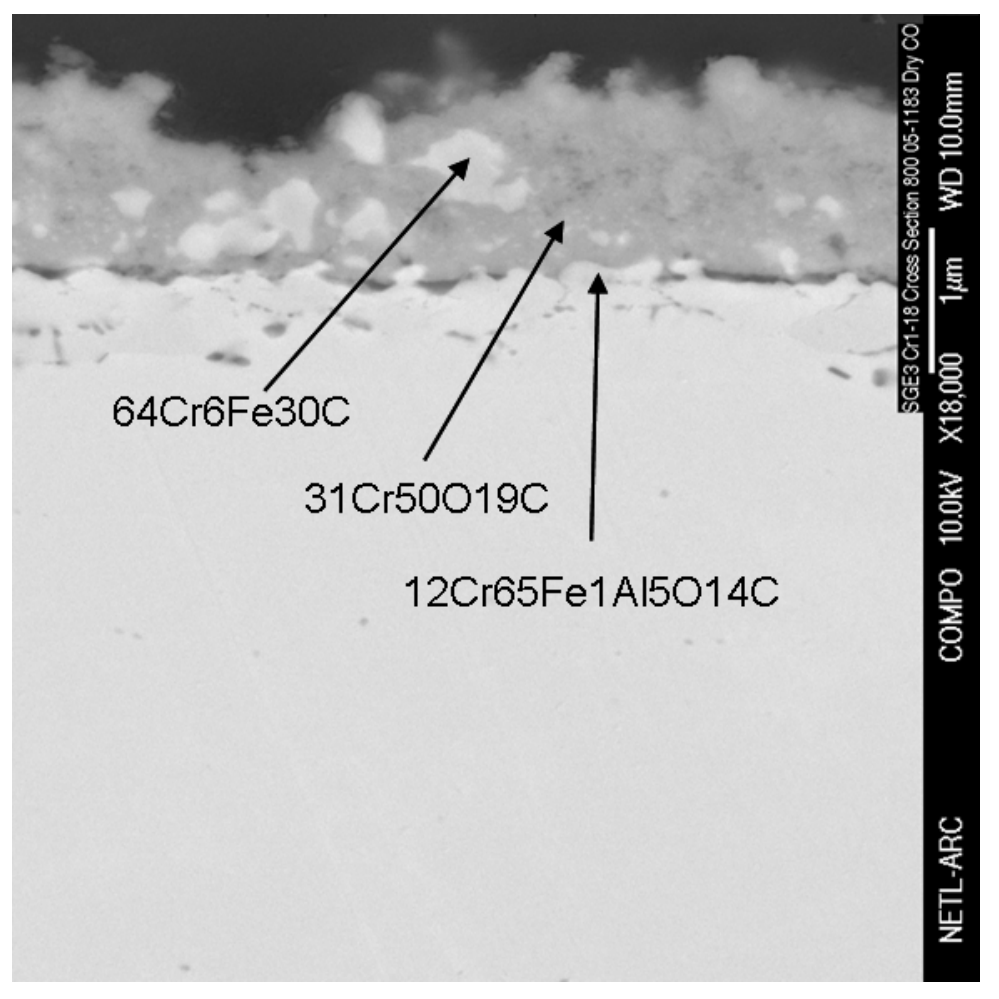




\section{The Analysis Element Diffusion}

- Solid Oxide Fuel Cell interconnect

- Using EDX and WDX together

- WDX used for low concentration elements, Ti, Al, Si

- Site lock option used to correct for drift.

- Sample mounting and grounding critical

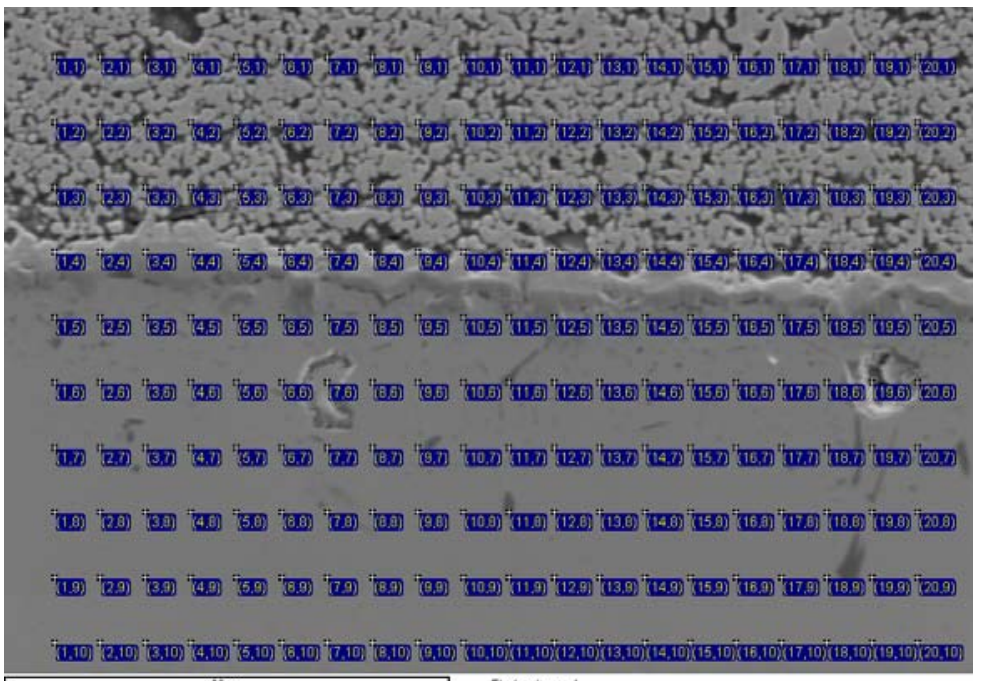




\section{The Analysis Element Diffusion}

- Solid Oxide Fuel Cell interconnect

- Beam currents 20 na

- Long dwell times 400s to detect diffusion of $\mathrm{Ti}, \mathrm{Al}$, and $\mathrm{Si}$

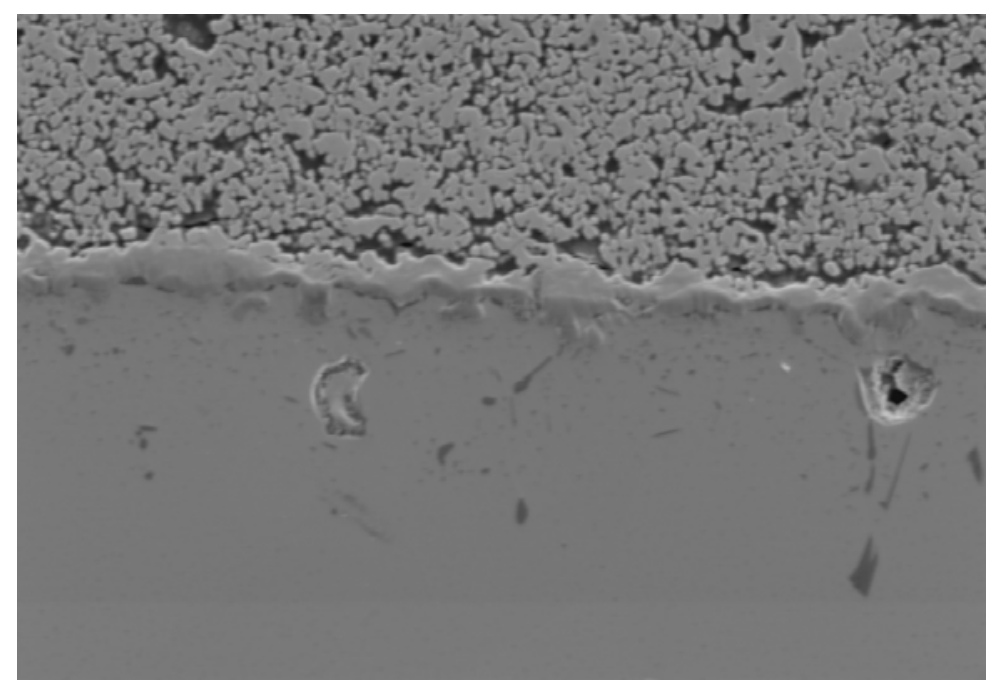

